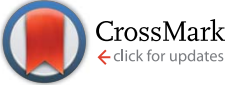

Cite this: Chem. Sci., 2017, 8, 1801

\title{
Halogen bonded Borromean networks by design: topology invariance and metric tuning in a library of multi-component systems $\uparrow$
}

\author{
Vijith Kumar, ${ }^{a}$ Tullio Pilati, ${ }^{a}$ Giancarlo Terraneo, ${ }^{a}$ Franck Meyer,,$^{a}$ \\ Pierangelo Metrangolo ${ }^{\mathrm{ab}}$ and Giuseppe Resnati ${ }^{\star a}$
}

\begin{abstract}
A library of supramolecular anionic networks showing Borromean interpenetration has been prepared by self-assembly of crypt-222, several metal or ammonium halides, and five bis-homologous $\alpha, \omega$-diiodoperfluoroalkanes. Halogen bonding has driven the formation of these anionic networks. Borromean entanglement has been obtained starting from all the four used cations, all the three used anions, but only two of the five used diiodoperfluoroalkanes. As the change of the diiodoperfluoroalkane, the cation, or the anion has a different relative effect on the metrics and bondings of the self-assembled systems, it can be generalized that bonding, namely energetic, features play here a less influential role than metric features in determining the topology of the prepared tetra-component cocrystals. This conclusion may hold true for other multi-component systems and may function as a general heuristic principle when pursuing the preparation of multi-component systems having the same topology but different composition.
\end{abstract}

Received 7th October 2016

Accepted 20th October 2016

DOI: $10.1039 / \mathrm{c} 6 s c 04478 f$

www.rsc.org/chemicalscience

feature of Borromean links lies in their intrinsic mode of

\section{Introduction}

To control the topological features of self-assembled systems is a key issue in many different fields related to basic sciences ${ }^{\mathbf{1}}$ and applied technologies. ${ }^{2}$ An example from application oriented studies is to avoid interpenetration and form metal-organic frameworks $^{3}$ (MOFs) or covalent organic frameworks ${ }^{4}$ (COFs) with large voids, both compound classes being promising materials for gas storage ${ }^{5}$ and sensing, ${ }^{6}$ mixture separation, ${ }^{7}$ and catalysis. ${ }^{8}$ An example from basic investigations, is the development of heuristic principles to control the supramolecular connectivity in catenanes, ${ }^{9}$ rotaxanes, ${ }^{10}$ and knots, ${ }^{11}$ the field having contributed strongly, during the last decade or so, to the terrific progress in the design of recognition and selfassembly processes in solution and in solids.

The Borromean rings ${ }^{\mathbf{1 2}}$ (Fig. 1, left) constitute a particularly fascinating pattern of topological entanglement ${ }^{13}$ where complexity, structural integrity, and aesthetic beauty are present in the final architecture. The distinctive topological

${ }^{a}$ Laboratory of Nanostructured Fluorinated Materials (NFMLab), Department of Chemistry, Materials, and Chemical Engineering "Giulio Natta", Politecnico di Milano, Via L. Mancinelli 7, 20131 Milano, Italy.E-mail: giuseppe.resnati@polimi.it ${ }^{b}$ VTT-Technical Research Centre of Finland, P. O. Box 1000, FI-02044 VTT, Finland $\dagger$ Electronic supplementary information (ESI) available: Materials and methods, NMR, DSC, powder and single crystal X-ray data. CCDC 1505909-1505934. For ESI and crystallographic data in CIF or other electronic format see DOI: 10.1039/c6sc04478f

\$ Present address: Laboratory of Biopolymers and Supramolecular Nanomaterials, Université Libre de Bruxelles, Boulevard du Triomphe, 1050 Bruxelles, Belgium. interpenetration: three mutually disjointed closed curves form a link, yet no two rings are linked; but if anyone is cut, the other two are free to separate.

This complex interwoven structure has inspired scientists from varied backgrounds $\mathbf{s}^{\mathbf{1 4}}$ and the first formation of discrete molecular Borromean rings was realized in 1997 by the effective manipulation of a DNA sequence. ${ }^{15}$ Subsequently, nanoscale Borromean rings were prepared by Stoddart et al. through the use, in concert, of metal coordination, supramolecular and dynamic covalent chemistry. ${ }^{\mathbf{1 6}}$ Infinite Borromean networks are frequently ${ }^{17}$ based on two-dimensional $(6,3)$ networks with undulating character. ${ }^{\mathbf{1 8}}$ It seems that the presence of large
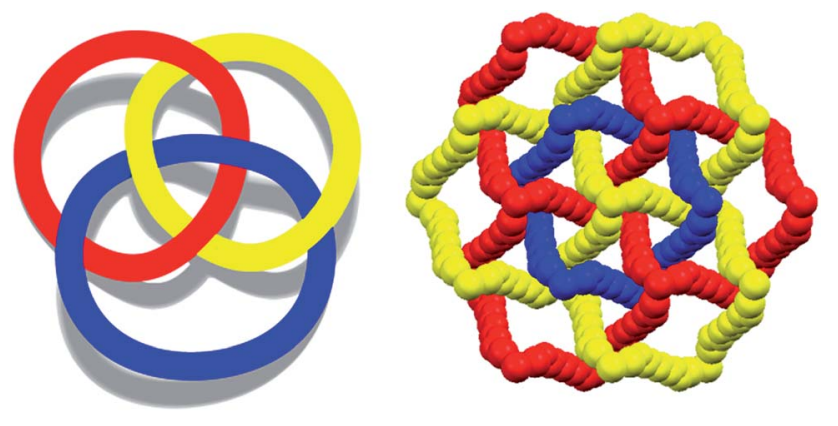

Fig. 1 Left: Schematic view of discrete Borromean ring. Right: Partial view (Mercury 3.8, space-filling) of the three honeycomb nets present in the cocrystal $1 \cdot 2 \mathrm{f} \cdot 3 \mathrm{~d}$. Red, yellow, and blue colours differentiate the three translationally related nets showing Borromean entanglement. Supercations $\mathrm{K}^{+} \subset 1$ are omitted for clarity. 
empty frames in Borromean networks is an essential requirement for entanglement. ${ }^{19}$ Coordination chemistry ${ }^{\mathbf{1 6 d 2 0}}$ has frequently driven the formation of non-trivial links, Borromean systems included. Also hydrogen bonds, ${ }^{21}$ argentophilic ${ }^{22}$ and $\pi-\pi$ interactions ${ }^{23}$ have been used, possibly in combination with coordination chemistry, to facilitate the formation and/or stabilization of the Borromean motif.

Halogen bonding $(\mathrm{XB})^{24}$ has consolidated its role as a powerful tools in crystal engineering. ${ }^{25}$ The available halogen bonded synthons are very diversified and both neutral and ionic motifs have been used to achieve a great variety of supramolecular architectures. ${ }^{26}$ Halide anions have been recognized as very good $\mathrm{XB}$ acceptors and have been used to form several halogen bonded networks with different topologies. ${ }^{27}$ For instance, self-assembly of bromide or chloride anions with carbon tetrabromide affords acentric adamantanoid networks presenting interesting non-linear optical properties ${ }^{28}$ and chloride anion effectively templated redox-active ferrocene catenanes in solution and a surface-confined environment. ${ }^{29}$

Some years ago we have demonstrated that self-assembly of 4,7,13,16,21,24-hexaoxa-1,10-diazabicyclo[8.8.8]hexacosane

(crypt-222, 1), potassium iodide (2f), and $\alpha, \omega$-diiodoperfluoroalkanes (3a-d) lead to the cocrystals $\mathbf{1} \cdot \mathbf{2 f} \cdot \mathbf{3 a}-\mathbf{d}$ (Fig. 2). ${ }^{30}$ $\mathrm{K}^{+}$cations are cryptated by $\mathbf{1}$ and the electron donor ability of $\mathrm{I}^{-}$ anions is boosted. These anions behave as tridentate $\mathrm{XB}$ acceptors and interact with three different diiodoperfluoroalkyl chains 3a-d which work as bidentate and telechelic XB donors. $(6,3)$ nets are formed where $\mathrm{I}^{-}$anions sit at the vertexes of the hexagonal frames and diiodoperfluoroalkanes form the sides (Fig. 3). In all four cocrystals these honeycomb nets produce layers which alternate with hydrocarbon layers formed by $\mathrm{K}^{+} \subset$ crypt-222 and iodide anions sitting at the layer interfaces. While in $\mathbf{1} \cdot \mathbf{2} \mathbf{f} \cdot \mathbf{3 a}, \mathbf{b}$ the fluorous layer contains a single honeycomb net, in $\mathbf{1} \cdot \mathbf{2 f} \cdot \mathbf{3 c}$,d it contains three $(6,3)$ nets showing Borromean entanglement supported by XB (Fig. 1, right).

Cocrystals $\mathbf{1} \cdot \mathbf{2} \cdot \mathbf{3}$ are obtained on self-assembly of three different chemical species (i.e., cryptand 1, salts 2 , and diiodoperfluoroalkanes 3 ) and four components (i.e., 1, the cation and anion from salts 2 , and 3 ) which can be varied independently.

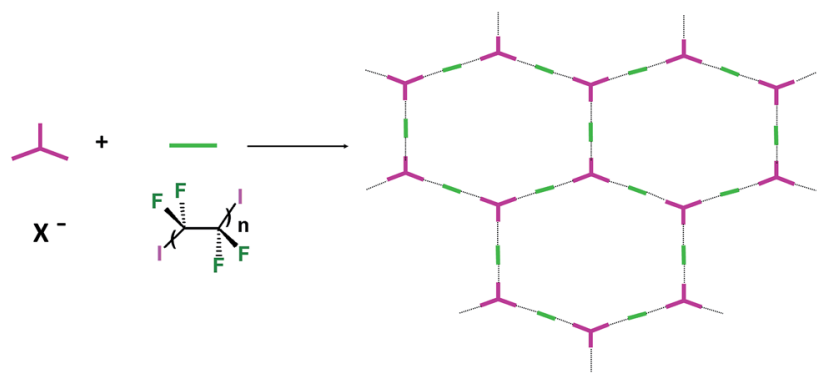

Fig. 3 Schematic representation of the XB driven self-assembly of diiodoperfluoroalkanes 3 with halide anions to form supramolecular anions with $(6,3)$ topology wherein anions are the nodes and diiodoalkanes the sides of the hexagonal frames.

The numerous possibilities to vary the composition of these tetracomponent cocrystals offer a unique opportunity to pursue the design and preparation of a library of different cocrystals wherein the halogen bonded supramolecular anions show Borromean entanglement. The challenge to prepare a library of cocrystals with Borromean interpenetration is a case of a quite general problem, i.e., how to change the composition of a multi-component and self-assembled system while maintaining unmodified its topology. It was expected that the change of only some of the dimensional and electronic characteristics in the items of a library of cocrystals $\mathbf{1} \cdot \mathbf{2} \cdot \mathbf{3}$ is compatible with the formation of nets showing Borromean entanglement. In other words, we expected that cocrystals "similar" to $\mathbf{1} \cdot \mathbf{2 f} \cdot \mathbf{3 c}, \mathbf{d}$ or $\mathbf{1} \cdot \mathbf{2 f} \cdot \mathbf{3 a}$, b would afford $(6,3)$ nets with or without Borromean interpenetration, respectively. In order to assess the chemical meaning of such similarity, we prepared a library of cocrystals $\mathbf{1} \cdot \mathbf{2} \cdot \mathbf{3}$ containing $\mathrm{Na}^{+}$, or $\mathrm{K}^{+}$, or $\mathrm{Rb}^{+}$, or $\mathrm{NH}_{4}^{+}$cations, $\mathrm{Cl}^{-}$, or $\mathrm{Br}^{-}$, or $\mathrm{I}^{-}$anions, and two-, or four-, or six-, or eight-, or ten- carbon diiodoperfluoroalkanes 3 (Fig. 2).

Different anions and cations give rise to XBs and electrostatic attraction between opposite ions (the two strongest interactions in cocrystals $\mathbf{1} \cdot \mathbf{2} \cdot \mathbf{3}$ ) endowed with quite different strength. This allowed us to assess the relevance of the bonding features in determining the connectivity and the

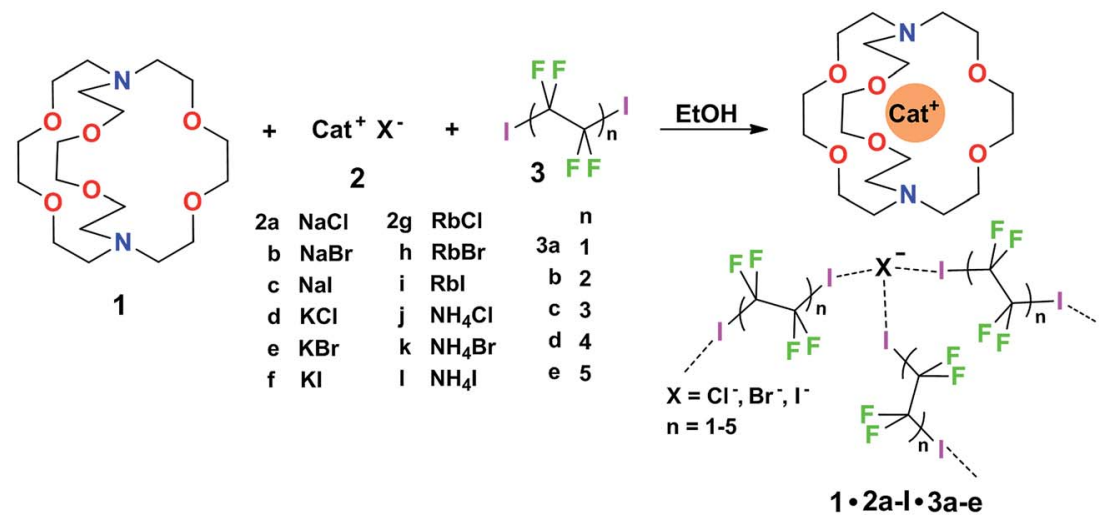

Fig. 2 Starting chemical species 1, 2a-l, and 3a-e and schematic representation of the structural units in corresponding cocrystals $1 \cdot 2 a-l \cdot 3 a-e$. A pattern of three XBs around the anion is depicted as it is the by far most common arrangement in the library (it is present in twenty eight of the thirty one $X$-ray structures). 
interpenetration in the formed cocrystals. In other words, this allowed us also to assess if the Borromean interpenetration tolerates non minor differences in the strength of interactions driving the cocrystals self-assembly.

As to the metric of cocrystals $\mathbf{1} \cdot \mathbf{2} \cdot \mathbf{3}$, our working hypothesis was that if the presence of large and void frames in a network is a prerequisite for its Borromean entanglement, diiodoperfluoroalkanes 3 were very promising candidates for obtaining a library of Borromean $(6,3)$ cocrystals $1 \cdot 2 \cdot 3$. 3a-e are expected to be the anion spacers in supramolecular anionic networks of cocrystals $\mathbf{1} \cdot \mathbf{2} \cdot \mathbf{3}$ (Fig. 3 ) and are also expected to behave as rigid and rod-like moieties, ${ }^{31}$ as it is typically the case for perfluoroalkyl derivatives. 3a-e are thus assumed to function as the most influential component in determining the metric of the networks. One or more of them were expected to be tailored to reliably afford $(6,3)$ networks sized for Borromean interpenetration independent of the cation and anion nature and a library of Borromean cocrystals $\mathbf{1} \cdot \mathbf{2} \cdot \mathbf{3}$ should be accessible.

The structures of obtained multicomponent cocrystals $\mathbf{1} \cdot \mathbf{2 a}-\mathbf{l} \cdot \mathbf{3 a}$-e determined via single crystal X-ray analyses (ESI, Tables S1-S5†) were numerous enough to map in the detail the overall architectural landscape as a function of the cocrystal composition and to identify the boundaries of the compositional space compatible with $(6,3)$ net formation and Borromean entanglement (Table 1). Borromean entanglement is present in twelve of the obtained cocrystals and this topology was formed starting from all four cations, all three anions, and only two of the five diiodoperfluoroalkanes 3 which have been used. This proves that the architectural features responsible for the Borromean entanglement in cocrystals $\mathbf{1} \cdot \mathbf{2} \cdot \mathbf{3}$ are robust

Table 1 Digits in the table are the number of cocrystals $1 \cdot 2 \cdot 3$ wherein the supramolecular anion adopts a non interpenetrated $(6,3)$ topology (green), a Borromean interpenetrated $(6,3)$ topology (red), and other topologies (blue) as a function of cationic (upper five lines) and anionic components (lower five lines) and of $\alpha, \omega$,-diiodoperfluoroalkanes 3 (columns)

\begin{tabular}{|c|c|c|c|c|c|c|}
\hline \multirow[t]{2}{*}{$\begin{array}{l}\text { Cocrystals } \\
\text { component }\end{array}$} & \multicolumn{2}{|c|}{$\begin{array}{l}\text { Non- } \\
\text { Interpenetrated } \\
(6,3) \text { networks }\end{array}$} & \multicolumn{2}{|c|}{$\begin{array}{c}\text { Borromean } \\
\text { interpenetrated } \\
(6,3) \text { networks } \\
\end{array}$} & \multicolumn{2}{|c|}{$\begin{array}{l}\text { Other } \\
\text { topologies }\end{array}$} \\
\hline & $3 \mathbf{a} ; \mathbf{3 b}$ & 3c; 3d & $\mathbf{3 a} ; \mathbf{3 b}$ & 3c; $3 \mathbf{d}$ & $\mathbf{3 a} ; \mathbf{3 b}$ & $\mathbf{3 c} ; \mathbf{3 d}$ \\
\hline $\mathrm{Na}^{+}$ & $3 ; 1$ & $2 ;-$ & $-;-$ & $-; 1$ & $-; 1^{a}$ & $1^{b} ; 1^{c}$ \\
\hline $\mathrm{K}^{+}$ & $1 ; 1$ & $-;-$ & $-;-$ & $1 ; 3$ & $-;-$ & $2^{b} ; 1^{d}$ \\
\hline $\mathrm{Rb}^{+}$ & $-;-$ & $-; 1$ & $-;-$ & $2 ; 1$ & $-;-$ & $1^{b} ;-$ \\
\hline $\mathrm{NH}_{4}^{+}$ & $1 ;-$ & $-;-$ & $-;-$ & $1 ; 3$ & $-; 1^{a}$ & $1^{b} ;-$ \\
\hline Total & \multicolumn{2}{|c|}{10} & \multicolumn{2}{|c|}{12} & \multicolumn{2}{|c|}{9} \\
\hline $\mathrm{Cl}^{-}$ & $1 ;-$ & $-;-$ & $-;-$ & $-; 2$ & $-; 1^{a}$ & $4^{b} ;-$ \\
\hline $\mathrm{Br}^{-}$ & $1 ; 1$ & $1 ; 1$ & $-;-$ & $1 ; 2$ & $-;-$ & $1^{b} ; 1^{c}$ \\
\hline $\mathrm{I}^{-}$ & $3 ; 1$ & $1 ;-$ & $-;-$ & $3 ; 4$ & $-; 1^{a}$ & $-; 1^{d}$ \\
\hline Total & \multicolumn{2}{|c|}{10} & \multicolumn{2}{|c|}{12} & \multicolumn{2}{|c|}{9} \\
\hline
\end{tabular}
$a(4,4)$ network. ${ }^{b}$ Ribbon of squares. ${ }^{c}$ Pearl necklace. ${ }^{d}$ Oligomers
formed by 1,10 -diiodoperfluorodecane $3 \mathbf{e}$. enough to hold up some variability in both the XB donor and acceptor modules, namely in both the metric and bonding features of the cocrystals. Considering the different relative effect that the change of the diiodoperfluoroalkane, the cation, or the anion has on metrics and bondings in cocrystals $\mathbf{1} \cdot \mathbf{2} \cdot \mathbf{3}$, it can be generalized that bonding, namely energetic, features play a less influential role than metrics in determining the topology of the multi-component systems under study. These conclusions may hold true for other multi-component systems and they may work as general heuristic principles when pursuing the preparation of multi-component cocrystals having the same topology but different composition.

\section{Results and discussion}

\section{Preparation of cocrystals $1 \cdot 2 a-1 \cdot 3 a-e$}

To correlate reliably the structural differences in $\mathbf{1} \cdot \mathbf{2} \mathbf{a}-\mathbf{1} \cdot \mathbf{3 a}-\mathbf{e}$ cocrystals with differences in the starting components, our preliminary experiments aimed at optimizing experimental conditions for the preparation of our cocrystals. The aim was to secure that the structure of the obtained systems was largely independent of the experimental conditions. This enabled us to draw general, robust, and safe conclusions on the composition vs. cocrystal topology relationships.

We selected five sets of starting tectons as representative of different possible self-assemblies; the two sets $\mathbf{1} / \mathbf{2 a} / \mathbf{3 a}$ and $\mathbf{1} / \mathbf{2} \mathbf{b}$ / $3 \mathbf{b}$ were expected to afford non-Borromean adducts for similarity with already reported cocrystals $1 \cdot 2 f \cdot 3 a, b$, while the three sets $\mathbf{1} / \mathbf{2 c} / \mathbf{3 d}, \mathbf{1} / \mathbf{2 h} / \mathbf{3 c}$, and $\mathbf{1} / \mathbf{2} \mathbf{j} / \mathbf{3 d}$ were expected to afford Borromean adducts. We first monitored, with the NMR technique, ethanol solutions containing the pure tectons mentioned above in a $1: 1: 1.5$ ratio, namely the stoichiometry of a $(6,3)$ network. ${ }^{1} \mathrm{H}$ and ${ }^{19} \mathrm{~F}$ spectra of these solutions after some hours at room temperature, confirmed cation cryptation occurred quite rapidly under adopted conditions (ESI, paragraph $\mathrm{S} 3 \dagger$ ). We then evaporated solutions wherein the $1: 2: 3$ ratio was $1: 1: 1.5$, $1: 1: 2$, and $1: 1: 1$ in order to assess how dependent the formed cocrystal was on the adopted stoichiometry. These studies have been performed on a set of four systems. DSC and powder X-ray analyses of the cocrystals (isolated at $25 \% \mathrm{ca}$. conversion) proved that, within the tested compositional range, the formed cocrystal was not affected by the solution stoichiometry (ESI, paragraphs S4 and $\mathrm{S} 5 \dagger$ ). We finally tried cocrystals formation starting from 1:1.5 molar solutions of cation $\subset$ crypt-222 halides and diiodoperfluoroalkanes. The analytical techniques mentioned above showed that the cocrystals formed after this protocol (at 25\% ca. conversion) were the very same as in previous experiments where pure tectons 1, 2, and 3 were mixed in a $1: 1: 1.5$ ratio.

Slow isothermal evaporation of the solvent from ethanol solutions of pure 1,2 , and 3 in a $1: 1: 1.5$ ratio was thus chosen as the standard protocol to prepare all the cocrystals. After 3-7 days at room temperature, colorless crystals were formed and IR analyses showed that $\nu_{\mathrm{C}-\mathrm{H}}$ stretchings were blue shifted with respect to pure starting 1 (typically at $2810-2970 \mathrm{~cm}^{-1}$ rather than at $2710-2940 \mathrm{~cm}^{-1}$ ), consistent with the presence of cation $\subset$ crypt-222 halides (ESI, S6 $\dagger$ ). The presence of 
diiodoperfluoroalkanes in the isolated cocrystals was proven, among others, by the $\nu_{\mathrm{C}-\mathrm{F}}$ stretching peaks in the 1085-1200 $\mathrm{cm}^{-1}$ region. These peaks were red shifted, compared to pure tectons 3, suggesting involvement in XB formation $\subset$ crypt-222 halides $(\mathbf{1} \cdot \mathbf{2}){ }^{32}$ These data indicate that, in all fifty two cases under study, halogen bonded cocrystals $\mathbf{1} \cdot \mathbf{2} \cdot \mathbf{3}$ were formed wherein the $\alpha, \omega$-diiodoperfluoroalkanes $\mathbf{3 a}-\mathbf{e}$ are the XB donors and the anion of cryptated salts $\mathbf{1} \cdot \mathbf{2 a}-\mathbf{l}$ are the acceptors. ${ }^{33}$ Melting points were different from starting tectons 1, 2, and 3 and from respective cation $\subset$ crypt-222 halides $(\mathbf{1} \cdot \mathbf{2})$. These data indicate that, in all fifty two cases under study, halogen bonded cocrystals $\mathbf{1} \cdot \mathbf{2} \cdot \mathbf{3}$ were formed wherein the $\alpha, \omega$-diiodoperfluoroalkanes $\mathbf{3 a}-\mathbf{e}$ are the XB donors and the anion of cryptated salts $\mathbf{1} \cdot \mathbf{2 a}-\mathbf{l}$ are the acceptors.

Thirty one out of the fifty two $\mathbf{1} \cdot \mathbf{2} \cdot \mathbf{3}$ adducts afforded samples suitable for single crystal X-ray analyses. Five cocrystals, specifically $\mathbf{1} \cdot \mathbf{2 f} \cdot \mathbf{3 a}-\mathbf{d}$ and $\mathbf{1} \cdot \mathbf{2 c} \cdot \mathbf{3 a}$ had already been reported $^{\mathbf{3 0 a , 3 3}}$ and the remaining twenty six structures are discussed here.

\section{Description of selected crystal structures}

General features. The well-known tendency of crypt-222 to encapsulate the medium sized cations used here accounts for the presence of cation $\subset$ crypt-222 units in all determined structures.

Diiodoperfluoroalkanes, the sides of the supramolecular anionic networks, function as bidentate and telechelic XB donors in all cocrystals but $\mathbf{1} \cdot \mathbf{2 f} \cdot \mathbf{3 e}$ where some diiododecane units work as monodentate XB donors.

Halide anions, the network nodes, function as tetradentate $\mathrm{XB}$ acceptors in $(4,4)$ nets ( 2 cocrystals) and in the discrete units present in $\mathbf{1} \cdot \mathbf{2 f} \cdot \mathbf{3 e}$. Halide anions work as tridentate XB acceptors in all other systems namely in those showing the presence of $(6,3)$ networks (twenty two cocrystals), ribbons of juxtaposed squares (five cocrystals), and pearl-necklace arrangements (one cocrystal).

$\mathrm{XB}$ and the electrostatic attraction between cations and halide anions are strong interactions in cocrystals $\mathbf{1} \cdot \mathbf{2} \cdot \mathbf{3}$ and affect their structure, but also segregation ${ }^{34}$ of fluorous and hydrocarbon components is ubiquitous and highly influential in determining the overall crystal packing. Fluoroalkyl chains segregate from cryptated cations in by far the majority of the cocrystals and halide anions typically sit at the interface of segregated domains. For instance, alternating fluorocarbon and hydrocarbon layers are formed by the discrete adducts of $\mathbf{1} \cdot \mathbf{2 f} \cdot \mathbf{3 e}$ (ESI, Fig. S10 $\dagger$ ), the pearl-necklaces of $\mathbf{1} \cdot \mathbf{2 b} \cdot \mathbf{3 d}$ (ESI, Fig. S11 $\dagger$ ), and all $(6,3)$ networks (ESI, Fig. S12 $\dagger$ ).

Non interpenetrated $(6,3)$ networks. Ten cocrystals adopt this topology which is the second most common in the prepared library (Table 1). Eight out of these ten systems are formed by $\mathbf{3 a}$ and $\mathbf{3 b}$, the short chain diiodoperfluoroalkanes. Remarkable similarities exist in all ten structures (ESI, Fig. S13-16†) and cocrystals formed by sodium chloride, bromide, and iodide (2a, $\mathbf{2 b}$, and $2 \mathbf{c}$, respectively) with diiodotetrafluoroethane $3 \mathbf{a}$ will be analyzed here in the details.

Similar to analogous systems,${ }^{27} \mathrm{XBs}$ are approximately on the extension of the C-I covalent bond, as expected for strong XBs $\left(\mathrm{C}-\mathrm{I} \cdots \mathrm{X}^{-}\right.$angles span the range $\left.167.81-179.58^{\circ}\right) . \mathrm{I}^{\cdots} \mathrm{X}^{-} \cdots \mathrm{I}$ angles are $76.68^{\circ}, 74.60^{\circ}$, and $72.16^{\circ}$ in $\mathbf{1} \cdot \mathbf{2 a} \cdot \mathbf{3 a}, \mathbf{1} \cdot \mathbf{2 b} \cdot \mathbf{3 a}$, and $\mathbf{1} \cdot \mathbf{2 c} \cdot 3 \mathbf{a}$, respectively, and the resulting pyramidal arrangement around halides determines an egg tray shape in the $(6,3)$ nets. The larger angle associated with the smaller halide allows for framing cavities of relatively constant size on halide change and the importance of this issue will be discussed in detail in one of the following paragraphs. Cryptated cations are sitting in these cavities. Fluorous layers in these systems formed by short-chain diiodoperfluorocarbons always contain a single honeycomb net.

$(6,3)$ networks with Borromean interpenetration. This topology is found in twelve cocrystals, namely this is the most frequently occurring topology in the library (Table 1).

The packings of all these cocrystals are nearly isostructural (Fig. 4), ten cocrystals being in the $P \overline{3}$ space group. Notably, this space group is adopted also by the Borromean cocrystal $\mathbf{1} \cdot \mathbf{2} \mathbf{j} \cdot \mathbf{3 d}$ where a water molecule completes the first coordination sphere $^{35}$ of the chloride. A water molecule is present also in the coordination sphere of the bromide cocrystal $\mathbf{1} \cdot \mathbf{2 h} \cdot \mathbf{3 c}$, and this
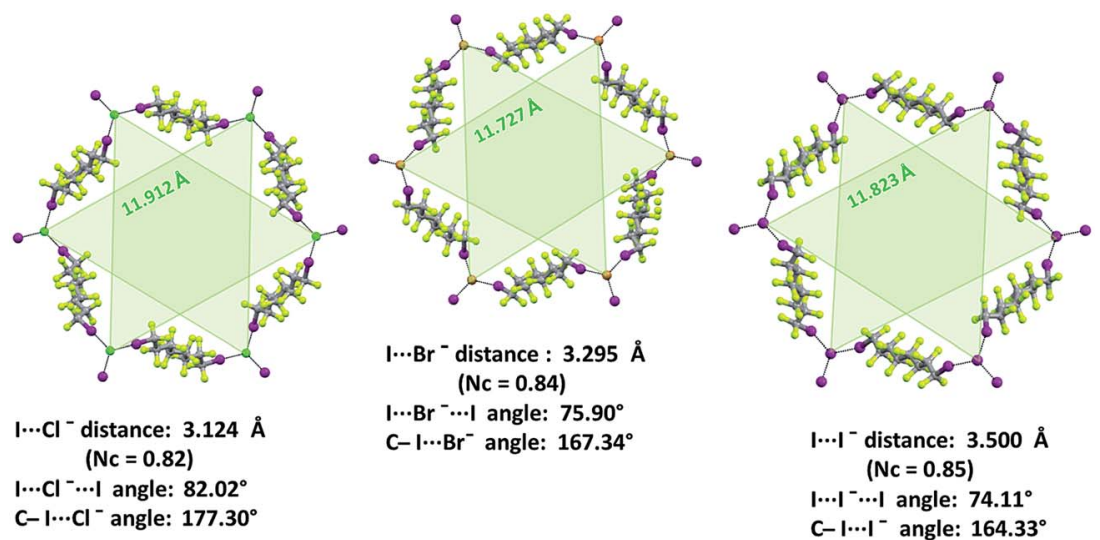

Fig. 4 Ball and stick representation (Mercury 3.8) of one hexagonal frame of the honeycomb net formed by diiodooctane $3 \mathrm{~d}$ with potassium chloride $1 \cdot 2 \mathrm{~d} \cdot \mathbf{3 d}$ (left), bromide $1 \cdot 2 \mathrm{e} \cdot \mathbf{3 d}(\mathrm{mid})$, and iodide $1 \cdot 2 \mathrm{f} \cdot \mathbf{3 d}$ (right). Semitransparent green triangles connect halide anions which are on the same side of the fluorous layer. Some key structural features are reported. Color codes: light green, fluorine; green, chlorine; brown, bromine; purple, iodine; grey, carbon. 
confirms that the tendency of $\mathbf{3 c}, \mathbf{d}$ to form Borromean $(6,3)$ networks is quite robust.

$\mathrm{XB}$ features parallel those described above for non-interpenetrated $(6,3)$ nets (ESI, Fig. S12-S16 $\dagger$ ). For instance, C-I $\cdots \mathrm{X}^{-}$ angles are quite linear and $\mathrm{I} \cdots \mathrm{X}^{-} \cdots \mathrm{I}$ angles decrease when the weight of the halide increases $\left(\mathrm{I} \cdots \mathrm{X}^{-} \cdots \mathrm{I}\right.$ angles in $\mathbf{1} \cdot \mathbf{2} \mathbf{j} \cdot \mathbf{3 d}$, $\mathbf{1} \cdot \mathbf{2 k} \cdot \mathbf{3 d}$, and $\mathbf{1} \cdot \mathbf{2} \cdot \mathbf{3 d}$, are $83.15^{\circ}, 78.73^{\circ}, 74.92^{\circ}$, respectively). Moreover, the $\mathrm{I}^{\cdots} \cdot \mathrm{Br}^{-}$separation in $\mathbf{1} \cdot \mathbf{2} \mathbf{k} \cdot \mathbf{3 d}$ (326.1 pm which corresponds to a normalized contact ${ }^{36} N_{\mathrm{c}}$ of 0.83 ) is longer than the $\mathrm{I}^{\cdots} \mathrm{Cl}^{-}$separation in $\mathbf{1} \cdot \mathbf{2} \mathbf{j} \cdot \mathbf{3 d}\left(310.8 \mathrm{pm}, N_{\mathrm{c}}=0.82\right)$ but shorter than the $\mathrm{I} \cdot \mathrm{I}^{-}$one in $\mathbf{1} \cdot \mathbf{2 l} \cdot \mathbf{3 d}\left(347.3 \mathrm{pm}, N_{\mathrm{c}}=0.84\right)$. This scale parallels the relative size of the different anions and is consistent with theoretical studies in the gas phase ${ }^{37}$ and some experimental studies ${ }^{38}$ in solution showing that, with a given $\mathrm{XB}$ donor, $\mathrm{Cl}^{-}$gives shorter and stronger $\mathrm{XB}$ than $\mathrm{Br}^{-}$which gives shorter and stronger XB than $\mathrm{I}^{-}$.

In Borromean systems a fluorous layer is formed by three translationally related honeycomb nets which entangle in a $2 \mathrm{D}$ $\rightarrow$ 2D fashion (Fig. 5 and 6). The chair-like shape of hexagonal frames, resulting from the pyramidal geometry at halide nodes and responsible for the egg tray arrangement of single nets, creates conditions for interpenetration. The typical stiffness of perfluoroalkyl chains, ${ }^{31}$ forming the sides of the hexagonal rings, helps in maintaining the large polymeric mesh of hexagonal frames which is a prerequisite for entanglement of three honeycomb nets.

The electrostatic attraction between cations and halide anions is a strong interaction in $\mathbf{1} \cdot \mathbf{2} \cdot \mathbf{3}$ cocrystals. On cation and anion change the separation of these charged species in the packing undergoes minor changes and the overall crystal packing remains quite constant. The convenient sizing of the cavities of the honeycomb grid is enabled primarily by the size of diiodoperfluoroalkane 3 and is tuned by the flexibility around the node of the hexagonal units. In fact, on $\mathrm{X}^{-}$change, minor changes are observed in $\mathrm{X}^{-} \cdots \mathrm{X}^{-}$separations (they are 11.823, 11.727, and $11.912 \AA$ in $\mathbf{1} \cdot \mathbf{2 f} \cdot \mathbf{3 d}, \mathbf{1} \cdot \mathbf{2 e} \cdot \mathbf{3 d}$, and $\mathbf{1} \cdot \mathbf{2 d} \cdot \mathbf{3 d}$, respectively), $\mathrm{K}^{+} \cdots \mathrm{K}^{+}$separations (they are $7.194,7.163$, and $7.202 \AA$ for the same derivatives as above), and $\mathrm{X}^{-} \cdots \mathrm{K}^{+}$separations (they are 6.939, 6.913, and $7.126 \AA$ for the same cocrystals

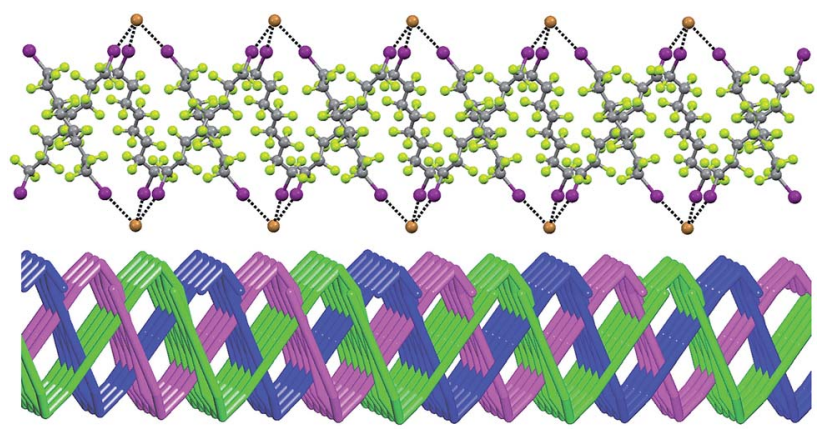

Fig. 5 Top: Partial representation along the crystallographic a-axis (Mercury 3.8, ball and stick) of one undulating honeycomb net in $1 \cdot 2 \mathrm{e} \cdot 3 \mathrm{~d}$. XBs are in black dotted lines. Colour codes as in Fig. 4. Bottom: Schematic view (approximately along the a-axis) of three entangled $(6,3)$ networks in the same compound; three different colours have been used for the three different nets.

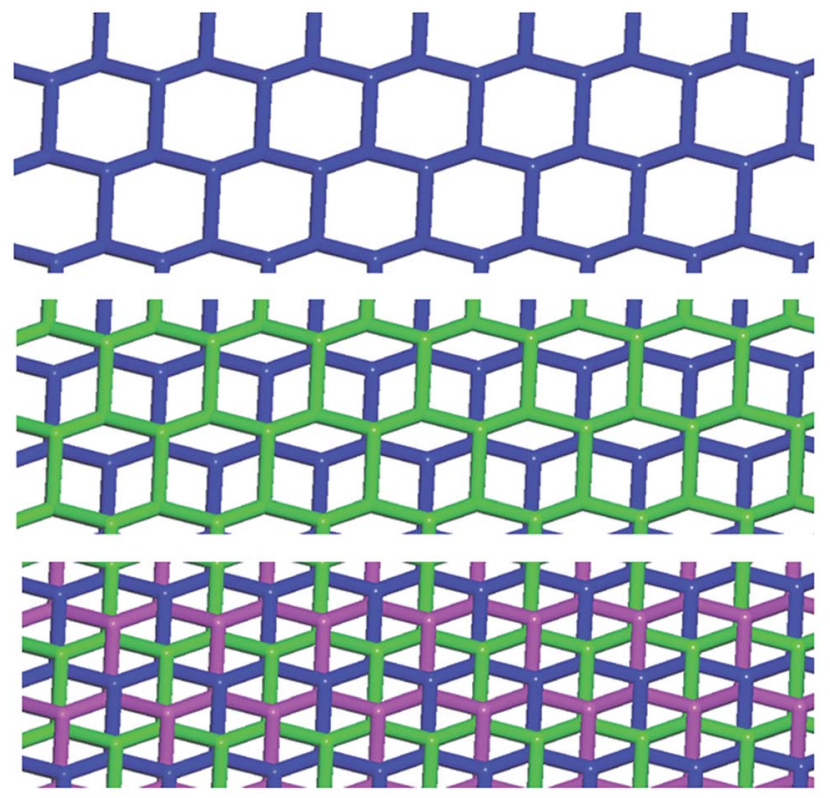

Fig. 6 Superimposition of three honeycomb nets, viewed along the $c$ axis, evidencing their Borromean interpenetration in $1 \cdot 2 \mathrm{e} \cdot 3 \mathrm{~d}$. Top: View of one honeycomb net; mid: a second net (green) is superimposed evidencing that the nets are not interlaced; bottom: the third net (violet) is added and it interlaces the other two as typical for Borromean systems.

as above). Differently, $\mathrm{I} \cdots \mathrm{X}^{-} \cdots \mathrm{I}$ angles show remarkable variability when $\mathrm{X}^{-}$changes (they are $73.08^{\circ}$ in $\mathbf{1} \cdot \mathbf{2 f} \cdot \mathbf{3 d}, 75.92^{\circ}$ in $\mathbf{1} \cdot \mathbf{2} \cdot \mathbf{3 d}$, and $82.02^{\circ}$ in $\mathbf{1} \cdot \mathbf{2 d} \cdot \mathbf{3 d}$ ). These geometric features help in rationalizing the topological invariance in the Borromean systems on component change. Chloride anion is the smallest anion of the $\mathbf{1} \cdot \mathbf{2 d}-\mathbf{f} \cdot \mathbf{3 d}$ series and consistent with its ability to form strong XBs, ${ }^{37,38} \mathrm{XBs}$ in the chloride cocrystal $\mathbf{1} \cdot \mathbf{2 d} \cdot \mathbf{3 d}$ are shorter than in other halide cocrystals $\mathbf{1} \cdot \mathbf{2 e}, \mathbf{f} \cdot \mathbf{3 d}$. In $\mathbf{1} \cdot \mathbf{2 d} \cdot \mathbf{3 d}$, hexagonal units large enough to ensure interpenetration are assembled by flattening the hexagonal frame relative to $\mathbf{1} \cdot \mathbf{2 e}, \mathbf{f} \cdot \mathbf{3 d}$ namely by widening $\mathrm{I} \cdots \mathrm{X}^{-} \cdots \mathrm{I}$ angles which, for the chloride, are $82^{\circ}$, the widest angle of the series $\mathbf{1} \cdot \mathbf{2 d}-\mathbf{f} \cdot \mathbf{3 d}$. In other words, the increased separation of perfluoroalkyl chains resulting from widening of the angles at the nodes in $\mathbf{1} \cdot \mathbf{2 d} \cdot \mathbf{3 d}$ counterbalances contraction of the hexagonal frames resulting from the small chloride size and the short XBs it forms. For the same reasons $\mathrm{I} \cdots \mathrm{Br}^{-} \cdots \mathrm{I}$ angles are smaller than $\mathrm{I}^{\cdots} \mathrm{I}^{-} \cdots \mathrm{I}$ angles. The isostructurality in the Borromean networks thus results from a fine balance between synthons size, strength, and flexibility (Fig. 7).

Other topologies. The overall architecture of the pearl necklace $\mathbf{1} \cdot \mathbf{2 b} \cdot \mathbf{3 d}$ shows some similarities with Borromean architectures, for instance halide anions function as tridentate and pyramidal XB acceptors in both topologies. Indeed, cocrystal $\mathbf{1} \cdot \mathbf{2 b} \cdot \mathbf{3 d}$ can be understood as a frustrated Borromean system (Fig. 8, ESI S17 and S18 $\dagger$ ) as the anion positions in $\mathbf{1} \cdot \mathbf{2 b} \cdot \mathbf{3 d}$ are quite similar to Borromean systems. The specific connectivity of the networks nodes in $\mathbf{1} \cdot \mathbf{2 b} \cdot \mathbf{3 d}$ is the result of the very unusual conformation adopted by diiodooctane modules. In fact two gauche torsion angles are found along two 

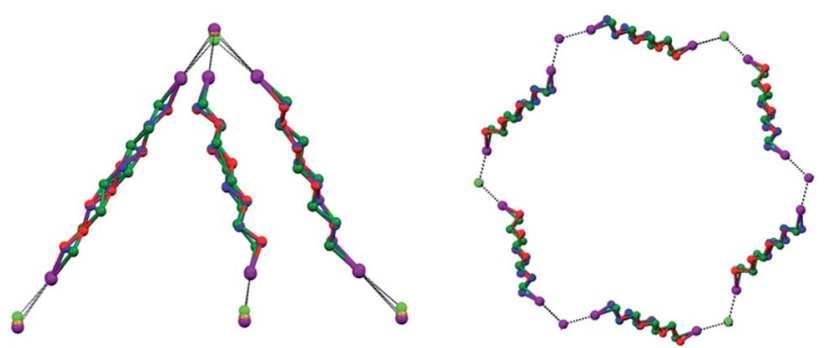

Fig. 7 Left: Superimposition of the trigonal nodes in $1 \cdot 2 d \cdot 3 d, 1 \cdot 2 e \cdot 3 d$, and $1 \cdot 2 f \cdot 3 d$, evidencing isostructurality. Fluorocarbon chains of modules $3 \mathrm{~d}$ are green colored in $1 \cdot \mathbf{2 d} \cdot \mathbf{3 d}$ cocrystal, blue colored in $1 \cdot 2 \mathrm{e} \cdot 3 \mathrm{~d}$, and red colored in $1 \cdot 2 \mathrm{f} \cdot \mathbf{3 d}$, fluorine atoms are omitted; iodide, bromide, and chloride anions are purple, brown, and green, respectively. Right: Superimposition of one hexagonal unit of $1 \cdot 2 d \cdot 3 d$, $1 \cdot 2 \mathrm{e} \cdot 3 \mathrm{~d}$, and $1 \cdot 2 \mathrm{f} \cdot 3 \mathrm{~d}$. XB are black dotted lines. Color codes as left.
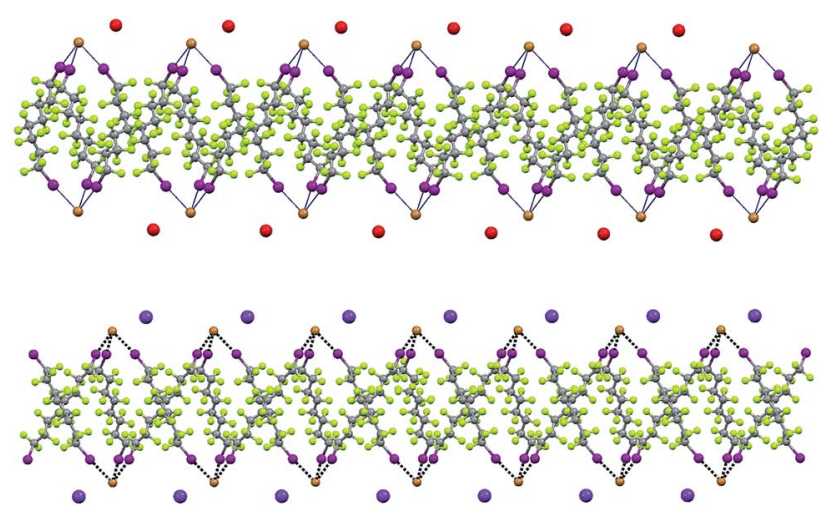

Fig. 8 Representation along the $b$ axis (Mercury 3.8, ball and stick) of one fluorous layer and adjacent cation layers formed by diiodoperfluorooctane $3 \mathrm{~d}$ with cryptated sodium bromide $(1 \cdot 2 b \cdot 3 \mathrm{~d}$, top) or potassium bromide $(1 \cdot 2 \mathrm{e} \cdot 3 \mathrm{~d}$, bottom). The structural similarity of the pearl necklace (top) and Borromean system (bottom) are apparent. Crypt-222 molecules have been omitted for sake of clarity. Color codes: grey, carbon; green, fluorine; brown, bromine; purple, iodine; red, sodium; violet, potassium.

of the crystallographically independent diiodoperfluorooctyl chains of $\mathbf{1} \cdot \mathbf{2 b} \cdot \mathbf{3 d}$ while perfluoroalkyl chains typically adopt a distorted anti-periplanar and zig-zag arrangement. ${ }^{31}$ The reduced length of the perfluoroalkyl chain possibly prevents the connectivity of the nodes enabling the formation of large frames and Borromean interpenetration.

In the five cocrystals wherein linear ribbons are present (Fig. 9), the ratio of starting tectons 1,2 , and 3 is $1: 1: 1.5$ and halide anions function as tridentate $\mathrm{XB}$ acceptors, once again as in Borromean nets. These ribbons are formed by juxtaposed squares having anions at the vertexes, diiodoperfluoroalkanes at the sides, and cations hosted in the squares. The topology observed in these structures is related to the nearly planar and $\mathrm{T}$ shaped geometry adopted by the anions (Fig. 9). In all five structures the $\mathrm{XB}$ donor is the diiodoperfluorohexane $\mathbf{3 c}$ while the cation can be any one of the four used in this paper and the anion either a chloride or a bromide. This confirms that the combined action of the size of the diiodoperfluoroalkane modules $\mathbf{3}$ and the flexibility, namely the angles, at the nodes is
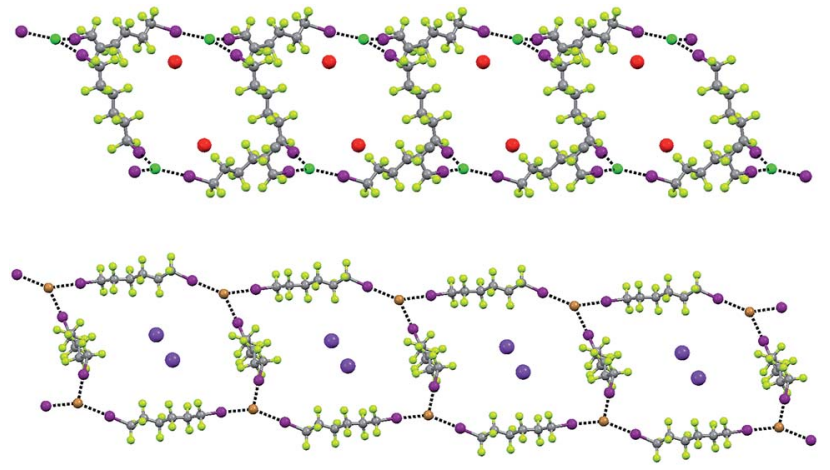

Fig. 9 Representation (Mercury 3.8, ball and stick) of one ribbon of squares formed by diiodoperfluorohexane $3 \mathrm{c}$ and cryptated sodium chloride $(1 \cdot 2 \mathrm{a} \cdot 3 \mathrm{c}$, top) and potassium bromide $(1 \cdot 2 \mathrm{e} \cdot 3 \mathrm{c}$, bottom). Crypt-222 molecules have been omitted for sake of clarity. Color codes: grey, carbon; light green, fluorine; green, chlorine; brown, bromine; purple, iodine; red, sodium; violet, potassium.

quite influential for the topology adopted by supramolecular anions.

Finally, in $\mathbf{1} \cdot \mathbf{2 a} \cdot \mathbf{3 b}, \mathbf{1} \cdot \mathbf{2} \mathbf{\mathbf { l }} \cdot \mathbf{3} \mathbf{b}$, and $\mathbf{1} \cdot \mathbf{2 f} \cdot \mathbf{3 e}$ halide anions function as tetradentate XB acceptors. In the first cocrystal anions are connected into square and planar $(4,4)$ networks hosting one cryptated cation at the center of the square frame (ESI, Fig. S19†). Similar but undulated $(4,4)$ networks are present in $\mathbf{1} \cdot \mathbf{2 l} \cdot \mathbf{3 b}$ while in $\mathbf{1} \cdot \mathbf{2 f} \cdot \mathbf{3 e}$ iodide anions adopt a distorted tetrahedral geometry and assemble well defined supramolecular anions through short I $\cdots X$ XBs. These supra-anions further interact with each other to give infinite chains via loose C-I $\cdots$ I-C XBs (ESI, Fig. S10, S20 and S21†).

\section{Topology of cocrystals $1 \cdot 2 \cdot 3$ as a function of starting components}

Cryptated cation. All the four cations populate the two most common topologies of the supramolecular anions, i.e., the $(6,3)$ networks showing Borromean entanglement and the noninterpenetrated $(6,3)$ networks (Table 1 ). This is consistent with the fact that the cation nature, while indirectly affecting the topology of the supramolecular anion in cocrystals $1 \cdot 2 \cdot 3$ via the cation-anion electrostatic attraction, is not the decisive element in determining such a topology. ${ }^{39}$

A detailed comparison of the topologies of halogen bonded supramolecular anions in sets of cocrystals containing given cations but different anions and/or diiodoperfluorocarbons, further indicates that the size of the cation influences the metric of the cocrystals but it does not affect it to the point of becoming the most influential factor for the topology adopted by the halogen bonded supramolecular anion. For instance, $\mathrm{Na}^{+} \subset$ crypt222 , the smallest cryptated cation in the examined series, ${ }^{39}$ affords a supramolecular anion with Borromean interpenetration (i.e., $\mathbf{1} \cdot \mathbf{2 c} \cdot \mathbf{3 d}$ ) only when the large iodide anion is the $\mathrm{XB}$ acceptor and the long diiodoperfluorooctane $\mathbf{3 d}$ is the $\mathrm{XB}$ donor. Smaller $\mathrm{XB}$ acceptors, namely bromide and chloride anions, and shorter $\mathrm{XB}$ donors, e.g., diiodoperfluoroalkanes $\mathbf{3 c}$ or $\mathbf{3 b}$, form non- 
interpenetrated $(6,3)$ networks $($ e.g., $\mathbf{1} \cdot \mathbf{2 a} \cdot \mathbf{3 c}, \mathbf{1} \cdot \mathbf{2 b} \cdot \mathbf{3} \mathbf{c}$, and $\mathbf{1} \cdot \mathbf{2 c} \cdot 3 \mathbf{b})$ when self-assembling with $\mathrm{Na}^{+} \subset$ crypt-222.

In general, cations are very effective in determining recognition phenomena and the structure of templated systems, ${ }^{40}$ but the data described above consistently prove that in our systems, Borromean interpenetration appears only when the formation of hexagonal frames with large enough meshes is secured by the synergistic action of the size of the cation, the anion, and the diiodoperfluoroalkane, the size of the diiodoalkane playing the most influential role.

Halide anion. In general, different anions can span quite different sizes, shapes, and coordination spheres ${ }^{\mathbf{4 1}}$ and they can template correspondingly different self-assembled structures. Sizes of halide anions vary from 119 to $206 \mathrm{pm}$ (from fluoride to iodide anions when having octahedral coordination) but they are all spherical, namely they have no major directional preference in their coordination spheres. Different halides can drive the formation of different structures when involved in electrostatic interactions, metal coordination, and hydrogen bonding, ${ }^{42}$ but, more frequently, they behave similarly. ${ }^{\mathbf{1 1 b , 4 3}}$ The same holds when halogen bonding is the driving force of the self-assembly. ${ }^{27,44}$ It is thus not surprising that all the three anions populate the two more common topologies of the supramolecular anion in cocrystals $\mathbf{1} \cdot \mathbf{2} \cdot \mathbf{3}$. The overall Borromean topology being poorly sensitive to the anion change implies that the architectural features responsible for the Borromean entanglement are robust enough to hold up some variability in the $\mathrm{XB}$ acceptor module.

A pro-active role of halide anions in the formation of Borromean interpenetrated systems is related to their spherical nature which allows the $\mathrm{I} \cdots \mathrm{X}^{-} \cdots \mathrm{I}$ angles to be wider for lighter halides in order to slightly flatten the $(6,3)$ networks and to counterbalance the smaller size of the hexagonal frames formed by lighter halides. For instance, the $\mathrm{I} \cdots \mathrm{X}^{-} \cdots \mathrm{I}$ angles are $73.47^{\circ}$

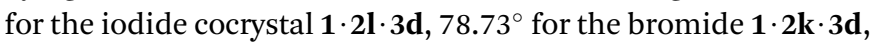
and 83.15 for the chloride $\mathbf{1} \cdot \mathbf{2 j} \cdot \mathbf{3 d}$. In this way, the egg tray shaped supramolecular anion contains cavities conveniently sized for Borromean entanglement.

In the four cocrystals $1 \cdot 2 a \cdot 3 c, 1 \cdot 2 d \cdot 3 c, 1 \cdot 2 g \cdot 3 c$, and $\mathbf{1} \cdot 2 \mathbf{j} \cdot \mathbf{3 c}$ wherein chloride anion is paired with diiodoperfluorohexane $\mathbf{3 c}$, the supramolecular anions are ribbons of squares (Fig. 9). In general, no chloride salt forms Borromean systems on selfassembly with diiodohexane 3c. This might be rationalized by considering that the flexibility described above at the halide nodes of supramolecular anions is not effective enough to afford adequately sized honeycomb frames on self-assembly of chloride anions, i.e., the smallest used halide, with diiodohexane $3 \mathbf{c}$, i.e., the shortest diiodoalkane able to give Borromean $(6,3)$ nets. In contrast, flexibility can afford adequately sized honeycomb frames on self-assembly of chloride anions with the longer diiodoperfluorooctane $\mathbf{3 d}$ (as it is the case in $\mathbf{1} \cdot \mathbf{2 d} \cdot \mathbf{3 d}$ and $\mathbf{1} \cdot \mathbf{2 j} \cdot \mathbf{3 d}$ ). ${ }^{45}$

Diiodoperfluoroalkane. The structure of the supramolecular anion in cocrystals $\mathbf{1} \cdot \mathbf{2} \cdot \mathbf{3}$ is decidedly dependent on the used diiodoperfluoroalkane. As reported in Table 1 , the different XB donors 3 populate in a different way the three topological groupings. For instance, all the five cocrystals formed by diiodoethane 3a show non-interpenetrated $(6,3)$ networks while diiodooctane $3 \mathbf{d}$ gives rise to one non-interpenetrated $(6,3)$ network, one $(4,4)$ network, one ribbon of squares, and eight Borromean systems. Diiodoperfluoroalkanes 3a-e are quite similar in relation to their supramolecular bonding features (i.e., the XBs they are involved in) and they differentiate each other for their respective size. As perfluoroalkyl chains are stiff moieties which typically adopt a distorted anti-periplanar and zig-zag arrangement, ${ }^{31}$ the five XB donors 3 are rod-like molecules in nearly all cocrystals $\mathbf{1} \cdot \mathbf{2} \cdot \mathbf{3}$ and the structural difference between two bis-homologues 3 translates into a change in the separation between the terminal iodine atoms of 22-24 pm $c a .^{31 a, b}$ This change seems particularly influential in determining the topology adopted by the supramolecular anion.

The presence of large cavities in a network is a prerequisite for Borromean entanglements. The size of the diiodoperfluorocarbon, which is the side of the network meshes, is the most important parameter in determining the meshes' metric. The diiodobutane $\mathbf{3 b}$ and the diiododecane $\mathbf{3} \mathbf{e}$ are the outer borders of the metric window enabling Borromean interpenetration. In other words, the former compound is too short and the latter is too long to form $(6,3)$ networks enabling Borromean interpenetration. Eight of the twelve systems showing this entanglement are formed by diiodoperfluorooctane 3d, namely its length seems better tailored to Borromean entanglement than diiodohexane $\mathbf{3 c}$.

While the presence of fluorine atoms in tectons 3 does not contribute directly to the formation of Borromean systems, e.g., by forming specific attractive interactions or by determining the size of the cavities in the supramolecular anions, fluorine gives major indirect contributions to such a formation. First, the presence of fluorine enables compounds $\mathbf{3}$ to dependably function as rigid and rod-like tectons and thus to determine unvaryingly the spacing metric of halide anions. Second, it boosts the XB donor ability of iodine atoms and allows them to drive reliably the formation of supramolecular and halogen bonded anions. Strong and regularly linear XBs are formed. This interaction directionality translates the tectons' geometry into a self-assembled architecture geometry, namely halide anions are typically pinned on the elongation of the diiodoperfluoroalkanes' molecular axis. Third, the presence of fluorine atoms favors the formation of layers containing more than one supramolecular anionic network, a prerequisite for interpenetration. This is due to the fact that perfluoroalkyl derivatives have a strong tendency to segregate, and this tendency increases with the length of the fluoroalkyl chain. ${ }^{\mathbf{4 6}}$ Interpenetration of the supramolecular anionic networks of a given layer is a way to increase segregation of their fluorous component while fulfilling the space filling requirements. Interestingly, thirteen cocrystals $\mathbf{1} \cdot \mathbf{2} \cdot \mathbf{3}$ contain interpenetrated supramolecular anions, one of them is formed by diiodobutane $\mathbf{3 b}$, four by diiodohexane $\mathbf{3 c}$, and eight by diiodooctane $\mathbf{3 d}$. The relative frequency of interpenetration clearly parallels the relative tendency of diiodoperfluoroalkanes 3 to segregate ${ }^{47}$ and the indirect relevance of fluorine to Borromean interpenetration is confirmed. 


\section{Conclusions}

Very few reports describe Borromean systems obtained by design ${ }^{16}$ as most cases of this entanglement have been identified via topological analyses of structures in the Cambridge Structural Database. ${ }^{19}$ This highlights the great challenge related to the design and obtainment of this topology.

Molecular interpenetration and entanglement are common phenomena in natural and human-made systems, spanning DNA and self-assembled coordination polymers. ${ }^{1,2,9-11}$ While the engineering of the benefits of these structural features in a system are still beyond routine approaches, the design and control of these features are particularly hot and timely in several fields of chemistry. We have reported here the XB driven self-assembly of a small library of nearly isostructural cocrystals containing supramolecular anionic networks endowed with Borromean interpenetration. XB has been confirmed as a reliable tool in the rational construction of entangled supramolecular assemblies with sophisticated topologies..$^{48}$ The reported results contribute to the field of anion-templated assembly of interpenetrated and interlocked structures, a field that has strongly contributed to some recent progresses of supramolecular chemistry. ${ }^{29,44,49}$

Borromean networks have been obtained starting from all the four used cations and all the three used anions, but only the diiodoperfluorohexane $\mathbf{3 c}$ and -octane $\mathbf{3 d}$. These results confirm the working hypotheses that some of the $\alpha, \omega$-diiodoperfluoroalkanes would afford regularly $(6,3)$ networks with frames sized to enable for Borromean interpenetration and that this can occur independent from the used cation and anion.

Two key structural features of diiodoperfluoroalkanes $\mathbf{3}$ for the obtainment of the Borromean systems are: (a) the rigid and rod-like character of diiodoperfluoroalkyl derivatives 3 , this character enabling $\mathbf{3 c}, \mathbf{d}$ to space halide anions after a dependable and useful metric; (b) the tendency of perfluoroalkyl motifs to segregate from hydrocarbon motifs, this tendency favoring the formation of fluorous layers containing more than one anionic network and the Borromean entanglement of these networks. A third structural feature which also contributes to the library preparation is the spherical character of halide anions, which helps in adjusting the geometry of XBs around the halides, namely in tuning the degree of pyramidalization at the nodes of the networks in order to form honeycomb frames with a convenient size.

In conclusion, the change of cations and anions in cocrystals $\mathbf{1} \cdot \mathbf{2} \cdot \mathbf{3}$ substantially affects the bonding features, namely the energetic aspects, in the self-assembled systems while it causes minor modifications of their metrics. On the other hand, the change of the diiodoperfluoroalkane is the most influential element for the metric of cocrystals $\mathbf{1} \cdot \mathbf{2} \cdot \mathbf{3}$ and has a minor effect on cation-anion attraction and on $\mathrm{XB}$, the two strong interactions in the cocrystals. Borromean interpenetration has been observed starting from all four cations, all three anions and only two of the five diiodoperfluoroalkanes. It thus seems that the metric features play a more influential role than energetic features in determining the topology of the tetra-component cocrystals described here. The applicability of this heuristic principle in the design and synthesis of other multi-component systems might be general and the usefulness of this principle in the self-assembly of crypt-111 (i.e., 4,10,15-trioxa-1,7-diazabicyclo[5.5.5]heptadecane), halide derivatives, and diiodoperfluoroalkanes is under assessment.

\section{Acknowledgements}

The authors would like to acknowledge the financial support of MIUR for grants PRIN 2010-2011 (projects no. 2010CX2TLM and no. 2010ERFKXL).

\section{Notes and references}

1 (a) Y. Inokuma, T. Ukegawa, M. Hoshino and M. Fujita, Chem. Sci., 2016, 7, 3910-3913; (b) M. Frank, M. D. Johnstone and G. H. Clever, Chem.-Eur. J., 2016, 22, 14104-14125; (c) H. S. Scott, N. Ogiwara, K. J. Chen, D. G. Madden, T. Pham, K. Forrest, B. Space, S. Horike, J. J. Perry IV, S. Kitagawa and M. J. Zaworotko, Chem. Sci., 2016, 7, 5470-5476; (d) J. F. Ayme, J. E. Beves, C. J. Campbell and D. A. Leigh, Angew. Chem., Int. Ed., 2014, 53, 7823-7827; (e) S. Zhang, H.-J. Sun, A. D. Hughes, R.-O. Moussodia, A. Bertin, Y. Chen, D. J. Pochan, P. A. Heiney, M. L. Klein and V. Percec, Proc. Natl. Acad. Sci. U. S. A., 2014, 111, 9058-9063; (f) M. W. Hosseini, Acc. Chem. Res., 2005, 38, 313-323.

2 (a) R. Tang, S. Zhou, Z. Cheng, G. Yu, Q. Peng, H. Zeng, G. Guo, Q. Li and Z. Li, Chem. Sci., 2016, DOI: 10.1039/ c6sc02956f; (b) H. J. Sun, S. Zhang and V. Percec, Chem. Soc. Rev., 2015, 44, 3900-3923; (c) S. Y. Zhang, W. Shi, P. Cheng and M. J. Zaworotko, J. Am. Chem. Soc., 2015, 137, 12203-12206; (d) Y. Horibe, J. Yang, Y. H. Cho, X. Luo, S. B. Kim, Y. S. Oh, F. T. Huang, T. Asada, M. Tanimura, D. Jeong and S. W. Cheong, J. Am. Chem. Soc., 2014, 136, 8368-8373; (e) S. Honda, T. Yamamoto and Y. Tezuka, J. Am. Chem. Soc., 2010, 132, 10251-10253; (f) E. R. Kay, D. A. Leigh and F. Zerbetto, Angew. Chem., Int. Ed., 2007, 46, 72-191.

3 (a) Y. C. Tan and H. C. Zeng, Chem. Commun., 2016, 52, 11591; (b) B. Volosskiy, K. Niwa, Y. Chen, Z. Zhao, N. O. Weiss, X. Zhong, M. Ding, C. Lee, Y. Huang and X. Duan, ACS Nano, 2015, 9, 3044-3049; (c) K. M. Choi, H. M. Jeong, J. H. Park, Y.-B. Zhang, J. K. Kang and O. M. Yaghi, ACS Nano, 2014, 8, 7451-7457; (d) N. Stock and S. Biswas, Chem. Rev., 2012, 112, 933-969; (e) D. Zhao, D. J. Timmons, D. Yuan and H.-C. Zhou, Acc. Chem. Res., 2011, 44, 123-133; (f) O. K. Farha and J. T. Hupp, Acc. Chem. Res., 2010, 43, 1166-1175.

4 (a) S. Dalapati, E. Jin, M. Addicoat, T. Heine and D. Jiang, J. Am. Chem. Soc., 2016, 138, 5797-5800; (b) P. J. Waller, F. Gándara and O. M. Yaghi, Acc. Chem. Res., 2015, 48, 3053-3063.

5 (a) D. Alezi, Y. Belmabkhout, M. Suyetin, P. M. Bhatt, Ł. J. Weseliński, V. Solovyeva, K. Adil, I. Spanopoulos, P. N. Trikalitis, A.-H. Emwas and M. Eddaoudi, J. Am. 
Chem. Soc., 2015, 137, 13308-13318; (b) A. J. Graham, D. R. Allan, A. Muszkiewicz, C. A. Morrison and S. A. Moggach, Angew. Chem., 2011, 50, 11138-11141.

6 (a) D. J. Wales, J. Grand, V. P. Ting, R. D. Burke, K. J. Edler, C. R. Bowen, S. Mintova and A. D. Burrows, Chem. Soc. Rev., 2015，44，4290-4321; (b) J.-S. Qin, D.-Y. Du, W.-L. Li, J.-P. Zhang, S.-L. Li, Z.-M. Su, X.-L. Wang, Q. Xu, K.-Z. Shao and Y.-Q. Lan, Chem. Sci., 2012, 3, 2114-2118.

7 (a) K. Raatikainen and K. Rissanen, Chem. Sci., 2012, 3, 12351239; (b) R. Matsuda, T. Tsujino, H. Sato, Y. Kubota, K. Morishige, M.Takata and S. Kitagawa, Chem. Sci., 2010, 1, 315-321.

8 (a) Z. Zhang, Y. Chen, S. He, J. Zhang, X. Xu, Y. Yang, F. Nosheen, F. Saleem, W. He and X. Wang, Angew. Chem., Int. Ed., 2014, 53, 12517-12521; (b) L. Meng, Q. Cheng, C. Kim, W.-Y. Gao, L. Wojtas, Y.-S. Chen, M. J. Zaworotko, X. P. Zhang and S. Ma, Angew. Chem., Int. Ed., 2012, 51, 10082-10085.

9 (a) T. Sawada, M. Yamagami, K. Ohara, K. Yamaguchi and M. Fujita, Angew. Chem., Int. Ed., 2016, 55, 4519-4522; (b) K. J. Hartlieb, A. K. Blackburn, S. T. Schneebeli, R. S. Forgan, A. A. Sarjeant, C. L. Stern, D. Cao and J. F. Stoddart, Chem. Sci., 2014, 5, 90-100; (c) N. H. Evans and P. D. Beer, Chem. Soc. Rev., 2014, 43, 4658-4683; (d) R. Hovorka, G. Meyer-Eppler, T. Piehler, S. Hytteballe, M. Engeser, F. Topic, K. Rissanen and A. Lützen, Chem.Eur. J., 2014, 20, 13253-13258.

10 (a) A. Vidonne, T. Kosikova and D. Philp, Chem. Sci., 2016, 7, 2592-2603; (b) J. D. Crowley, S. M. Goldup, A.-L. Lee, D. A. Leigh and R. T. McBurney, Chem. Soc. Rev., 2009, 38, 1530-1541; (c) J. P. Sauvage and C. D. Buchecker, Molecular Catenanes, Rotaxanes and Knots: A Journey Through the World of Molecular Topology, Wiley-VCH, Weinheim, 1999.

11 (a) K. E. Horner, M. A. Miller, J. W. Steed and P. M. Sutcliffe, Chem. Soc. Rev., 2016, DOI: 10.1039/c6cs00448b; (b) V. Marcos, A. J. Stephens, J. Jararnillo-Garcia, A. L. Nussbaumer, S. L. Woltering, A. Valero, J.-F. Lemonnier, I. J. V. Yrezabal and D. A. Leigh, Science, 2016, 352, 1555-1559; (c) J. F. Ayme, J. E. Beves, C. J. Campbell and D. A. Leigh, Chem. Soc. Rev., 2013, 42, 1700-1712.

12 (a) C. D. Pentecost, N. Tangchaivang, S. J. Cantrill, K. S. Chichak, A. J. Peters and J. Fraser Stoddart, J. Chem. Educ., 2007, 84, 855-859; (b) C. A. Schalley, Angew. Chem., Int. Ed., 2004, 43, 4399-4401.

13 R. S. Forgan, J. P. Sauvage and J. F. Stoddart, Chem. Rev., 2011, 111, 5434-5464.

14 G. Natarajan, A. Mathew, Y. Negishi, R. L. Whetten and T. Pradeep, J. Phys. Chem. C, 2015, 119, 27768-27785.

15 (a) C. Mao, W. Sun and N. C. Seeman, Nature, 1997, 386, 137138; (b) N. C. Seeman, Acc. Chem. Res., 1997, 30, 357-363.

16 (a) C. R. Yates, D. Benitez, S. I. Khan and J. F. Stoddart, Org. Lett., 2007, 9, 2433-2436; (b) A. J. Peters, K. S. Chichak, S. J. Cantrill and J. F. Stoddart, Chem. Commun., 2005, 3394-3396; (c) K. S. Chichak, A. J. Peters, S. J. Cantrill and J. Fraser Stoddart, J. Org. Chem., 2005, 70, 7956-7962; (d) S. J. Cantrill, K. S. Chichak, A. J. Peters and J. F. Stoddart,
Acc. Chem. Res., 2005, 38, 1-9; (e) K. S. Chichak, S. J. Cantrill, A. R. Pease, S. H. Chiu, G. W. V. Cave, J. L. Atwood and J. F. Stoddart, Science, 2004, 304, 1308-1312. 17 Q. X. Yao, X. H Jin, Z. F. Ju, H. X. Zhang and J. Zhang, CrystEngComm, 2009, 11, 1502-1504.

18 (a) X. L. Zhang, C. P. Guo, Q. Y. Yang, W. Wang, W. S. Liu, B. S. Kang and C. Y. Su, Chem. Commun., 2007, 4242-4244; (b) X. Q. Lu, M. Pan, J. R. He, Y. P. Cai, B. S. Kang and C. Y. Su, CrystEngComm, 2006, 8, 827-829.

19 (a) L. Carlucci, G. Ciani, D. M. Proserpio, T. G. Mitina and V. A. Blatov, Chem. Rev., 2014, 114, 7557-7580; (b) L. Carlucci, G. Ciani and D. M. Proserpio, Coord. Chem. Rev., 2003, 246, 247-289.

20 M. Pan and C. Y. Su, CrystEngComm, 2014, 16, 7847-7859.

21 (a) N. N. Adarsh and P. Dastidar, Cryst. Growth Des., 2010, 10, 483-487; (b) Y. B. Men, J. Sun, Z. T. Huang and Q. Y. Zheng, Angew. Chem., Int. Ed., 2009, 48, 2873-2876.

22 L. Dobrzanska, H. G. Raubenheimer and L. J. Barbour, Chem. Commun., 2005, 5050-5052.

23 M. P. Suh, H. J. Choi, S. M. So and B. M. Kim, Inorg. Chem., 2003, 42, 676-678.

24 (a) G. Cavallo, P. Metrangolo, R. Milani, T. Pilati, A. Priimagi, G. Resnati and G. Terraneo, Chem. Rev., 2016, 116, 2478-2601; (b) G. Berger, J. Soubhye and F. Meyer, Polym. Chem., 2015, 6, 3559-3580; (c) C. Robertson, R. N. Perutz, L. Brammer and C. A. Hunter, Chem. Sci., 2014, 5, 4179-4183; (d) G. R. Desiraju, P. S. Ho, L. Kloo, A. C. Legon, R. Marquardt, P. Metrangolo, P. Politzer, G. Resnati and K. Rissanen, Pure Appl. Chem., 2013, 85, 1711-1713.

25 (a) C. B. Aakeröy, T. K. Wijethunga, J. Benton and J. Desper, Chem. Commun., 2015, 51, 2425-2428; (b) P. Metrangolo, G. Resnati, T. Pilati and S. Biella, in Halogen Bonding. Fundamentals and Applications, ed. P. Metrangolo and G. Resnati, Springer-Verlag, Berlin, Heidelberg, 2008, vol. 126, pp. 105-136.

26 (a) C. C. Robertson, R. N. Perutz, L. Brammer and C. A. Hunter, Chem. Sci., 2014, 5, 4179-4183; (b) P. Metrangolo, F. Meyer, T. Pilati, G. Resnati and G. Terraneo, Angew. Chem., Int. Ed., 2008, 47, 6114-6127; (c) P. Metrangolo and G. Resnati, Chem.-Eur. J., 2001, 7, 2511-2519.

27 (a) J. Marti-Rujas, L. Meazza, G. K. Lim, G. Terraneo, T. Pilati, K. D. M. Harris, P. Metrangolo and G. Resnati, Angew. Chem., Int. Ed., 2013, 52, 13444-13448; (b) C. B. Aakeröy, M. Baldrighi, J. Desper, P. Metrangolo and G. Resnati, Chem.-Eur. J., 2013, 19, 16240-16247; (c) P. Metrangolo, T. Pilati, G. Terraneo, S. Biella and G. Resnati, CrystEngComm, 2009, 11, 1187-1196.

28 S. V. Lindeman, J. Hecht and J. K. Kochi, J. Am. Chem. Soc., 2003, 125, 11597-11606.

29 N. H. Evans, H. Rahman, A. V. Leontiev, N. D. Greenham, G. A. Orlowski, Q. Zeng, R. M. J. Jacobs, C. J. Serpell, N. L. Kilah, J. J. Davis and P. D. Beer, Chem. Sci., 2012, 3, 1080-1089.

30 (a) R. Liantonio, P. Metrangolo, F. Meyer, T. Pilati, W. Navarrini and G. Resnati, Chem. Commun., 2006, 1819- 
1821; (b) R. Liantonio, P. Metrangolo, T. Pilati and G. Resnati, Cryst. Growth Des., 2003, 3, 355-361.

31 (a) P. Metrangolo, T. Pilati, G. Resnati and A. Stevenazzi, Chem. Commun., 2004, 1492-1493; (b) G. Gattuso, A. Pappalardo, M. F. Parisi, I. Pisagatti, F. Crea, R. Liantonio, P. Metrangolo, W. Navarrini, G. Resnati, T. Pilati and S. Pappalardo, Tetrahedron, 2007, 63, 49514958.

32 (a) P. Cardillo, E. Corradi, A. Lunghi, S. V. Meille, M. T. Messina, P. Metrangolo and G. Resnati, Tetrahedron, 2000, 56, 5535-5550; (b) M. T. Messina, P. Metrangolo, W. Navarrini, S. Radice, G. Resnati and G. Zerbi, J. Mol. Struct., 2000, 524, 87-94.

33 G. Cavallo, P. Metrangolo, T. Pilati, G. Resnati, M. Ursini and G. Terraneo, Acta Crystallogr., Sect. E: Struct. Rep. Online, 2013, 69, m387-m388.

34 (a) Y.-C. Wu, P. Leowanawat, H.-J. Sun, B. E. Partridge, M. Peterca, R. Graf, H. W. Spiess, X. Zeng, G. Ungar, C.-S. Hsu, P. A. Heiney and V. Percec, J. Am. Chem. Soc., 2015, 137, 807-819; (b) H. Takezawa, T. Murase, G. Resnati, P. Metrangolo and M. Fujita, J. Am. Chem. Soc., 2014, 136, 1786-1788.

35 K. B. James, Acc. Chem. Res., 2005, 38, 671-678.

36 The normalized contact $N_{\mathrm{c}}$ is defined as the ratio $D_{\mathrm{XY}} /\left(r_{\mathrm{X}}+\right.$ $r_{\mathrm{Y}}$ ), where $D_{\mathrm{XY}}$ is the experimental distance between the halogen bonded iodine atoms $\mathrm{X}$ and halide anions $\mathrm{Y}$ and $r_{\mathrm{X}}$ and $r_{\mathrm{Y}}$ are the van der Waals radius for iodine and the Pauling ionic radius of the halide anion Y, respectively. $N_{\mathrm{c}}$ is a useful indicator of the relative interaction strength, more useful than the $\mathrm{XB}$ distance itself, because it allows distances between different interacting sites to be compared.

37 R. D. Walsh, J. M. Smith, T. W. Hanks and W. T. Pennington, Cryst. Growth Des., 2012, 12, 2759-2768.

38 (a) R. Tepper, B. Schulze, M. Jäger, C. Friebe, D. H. Scharf, H. Görls and U. S. Schubert, J. Org. Chem., 2015, 80, 31393150; (b) M. Cametti, K. Raatikainen, P. Metrangolo, T. Pilati, G. Terraneo and G. Resnati, Org. Biomol. Chem., 2012, 10, 1329-1333; (c) M. G. Sarwar, B. Dragisic, S. Sagoo and M. S. Taylor, Angew. Chem., Int. Ed., 2010, 49, 1674-1677.

39 It is interesting to observe that smaller cations seem more prone than larger cations to afford samples of cocrystals $\mathbf{1} \cdot \mathbf{2} \cdot \mathbf{3}$ suitable for single crystal X-ray analyses. The mean volumes of $\mathrm{Na}^{+} \subset$ crypt- $222, \mathrm{~K}^{+} \subset$ crypt- $222, \mathrm{Rb}^{+} \subset$ crypt- 222 , and $\mathrm{NH}_{4}{ }^{+} \subset$ crypt-222 in $\mathbf{1} \cdot \mathbf{2} \cdot \mathbf{3}$ cocrystals (measured via the volumes of polyhedra defined by the eight heteroatoms of crypt-222 1 in cocrystals $1 \cdot 2 \cdot 3$ ) are $24.404,28.547,32.494$, and $34.469 \AA^{3}$, respectively. A correlation clearly exists between the volume of the supramolecular cation cat $^{+} \subset$ crypt-222 and the volume of the non-cryptated cation afforded by salts 2 . When using 3a-d, the same set of cocrystals was tried for all cations, but sodium, potassium, ammonium, and rubidium afforded ten, seven, seven, and five single crystalline adducts, respectively.
40 Supramolecular Chemistry, ed. J. W. Steed and J. L. Atwood, Wiley, Chichester, 2nd edn, 2009, pp. 105-222.

41 (a) P. A. Gale and T. Gunnlaugsson, Chem. Soc. Rev., 2010, 39, 3595-3596; (b) Anion Receptor Chemistry, ed. J. L. Sessler, P. A. Gale and W. S. Cho, Royal Society of Chemistry, Cambridge, UK, 2006; (c) Special issue: Anion Coordination Chemistry II, ed. P. A. Gale, Coord. Chem. Rev., 2006, vol. 250, pp. 29173244.

42 (a) N. G. White and M. J. MacLachlan, Chem. Sci., 2015, 6, 6245-6249; (b) B. Hasenknopf, J. M. Lehn, B. O. Kneisel, G. Baum and D. Fenske, Angew. Chem., Int. Ed. Engl., 1996, 35, 1838-1840.

43 (a) T. U. Connell, S. Sandanayake, G. N. Khairallah, J. M. White, R. A. J. O'Hair, P. S. Donnelly and S. J. Williams, Dalton Trans., 2013, 42, 4903-4907; (b) M.-O. M. Piepenbrock, G. O. Lloyd, N. Clarke and J. W. Steed, Chem. Rev., 2010, 110, 1960-2004; (c) P. Diaz, D. Michael, P. Mingos, R. Vilar, A. J. P. White and D. J. Williams, Inorg. Chem., 2004, 43, 7597-7604; (d) D. Rais, J. Yau, D. Michael, P. Mingos, R. Vilar, A. J. P. White and D. J. Williams, Angew. Chem., Int. Ed., 2001, 40, 3464-3467.

44 For selective halide anions templated synthesis of catenane and rotaxanes under XB control see: (a) J. M. Mercurio, R. C. Knighton, J. Cookson and P. D. Beer, Chem.-Eur. J., 2014, 20, 11740-11749; (b) M. J. Langton, S. W. Robinson, I. Marques, V. Félix and P. D. Beer, Nat. Chem., 2014, 6, 1039-1043; (c) A. Caballero, F. Zapata, N. G. White, P. J. Costa, V. Fèlix and P. D. Beer, Angew. Chem., Int. Ed., 2012, 51, 1876-1880.

45 It is also interesting to observe that the heavier, namely more polarizable, the halide anion is, the more likely the obtainment of Borromean interpenetration becomes. Eight, nine, and fourteen single cocrystals $\mathbf{1} \cdot \mathbf{2} \cdot \mathbf{3}$ were obtained starting from chloride, bromide, and iodide anions, respectively, and one fourth, one third, and a half of these cocrystals present Borromean interpenetration, respectively.

46 (a) V. Ojogun, B. L. Knutson, S. Vyas and H. J. Lehmler, J. Fluorine Chem., 2010, 131, 784-790; (b) E. D. Wolf, P. Ruelle, J. V. D Broeke, B. J. Deelman and G. van Koten, J. Phys. Chem. B, 2004, 108, 1458-1466; (c) L. E. Kiss, I. Kövesdi and J. Rábai, J. Fluorine Chem., 2001, 108, 95-109. 47 Four, eleven, and eleven cocrystal $1 \cdot 2 \cdot 3$ have been formed by $\mathbf{3 b}, \mathbf{3 c}$, and $\mathbf{3 d}$, respectively. The probability to form interpenetrated anionic networks is thus $25 \%$ for $3 \mathbf{b}, 36 \%$ for $3 \mathbf{c}$, and $73 \%$ for $\mathbf{3 d}$.

48 (a) M. C. Pfrunder, A. S. Micallef, L. Rintoul, D. P. Arnold, K. J. P. Davy and J. McMurtrie, Cryst. Growth Des., 2012, 12, 714-724; (b) P. Metrangolo, F. Meyer, T. Pilati, D. M. Proserpio and G. Resnati, Chem.-Eur. J., 2007, 13, 5765-5772.

49 P. D. Beer, M. R. Sambrook and D. Curiel, Chem. Commun., 2006, 2105-2117. 